\title{
Effects of oral calcium supplementation on productive and reproductive performance in Holstein cows
}

\author{
N. Martinez, ${ }^{\ddagger} \ddagger$ L. D. P. Sinedino, ${ }^{*} \ddagger$ R. S. Bisinotto, ${ }^{\star} \ddagger$ R. Daetz,† C. A. Risco,† K. N. Galvão,†‡ \\ W. W. Thatcher, ${ }^{*} \ddagger$ and J. E. P. Santos ${ }^{*} \ddagger^{1}$ \\ *Department of Animal Sciences, \\ †Department of Large Animal Clinical Sciences, \\ fDH Barron Reproductive and Perinatal Biology Research Program, University of Florida, Gainesville 32611
}

\section{ABSTRACT}

The objectives of this experiment were to determine the effects of oral Ca supplementation on milk yield, body condition, pregnancy per artificial insemination (P/AI), and days to pregnancy in Holstein cows considered to be of low (LRM; no calving assistance, live singleton without retained placenta) or high (HRM; at least one of the following: dystocia, twins, stillbirth, retained placenta, or vulvo-vaginal laceration) risk of developing metritis. The hypotheses were that oral $\mathrm{Ca}$ supplementation during the early postpartum period would reduce the loss of body condition and improve lactation performance and reproduction. Four hundred fifty Holstein cows were blocked by parity as primiparous cows $(\mathrm{n}=174)$ or multiparous cows $(\mathrm{n}=276)$. Within parity, a cow considered at HRM was matched with a cow of LRM and the pair was randomly assigned to control (no Ca supplementation), $86 \mathrm{~g}$ of $\mathrm{Ca}$ on d 0 and 1 postpartum (CaS1), or $86 \mathrm{~g}$ of $\mathrm{Ca}$ on $\mathrm{d} 0$ and 1 postpartum followed by $43 \mathrm{~g} / \mathrm{d}$ on d 2 to 4 postpartum (CaS4). Body condition was scored at calving and 32 d postpartum and estrous cyclicity was evaluated at 38 and $52 \mathrm{~d}$ postpartum. Milk yield was recorded daily. Multiparous cows were classified as above or below the mean 305-d mature equivalent milk yield based on production in the previous lactation. Reproductive performance was evaluated for the first $210 \mathrm{~d}$ postpartum. Body condition did not differ among treatments, and cows lost on average 0.44 units of body condition in the first month of lactation. Calcium supplementation did not affect milk yield in the first 5 mo postpartum. For multiparous cows, Ca supplementation was beneficial to milk yield in the first 30 DIM in cows of greater production potential, but detrimental to multiparous cows with below average production potential. Calcium supplementation to primiparous cows reduced $\mathrm{P} / \mathrm{AI}$

Received October 15, 2015.

Accepted June 5, 2016.

${ }^{1}$ Corresponding author: Jepsantos@ufl.edu at first (control $=55.8, \mathrm{CaS} 1=31.5, \mathrm{CaS} 4=37.0 \%)$ and all artificial inseminations (control $=48.5, \mathrm{CaS} 1=$ 34.6 , CaS4 $=38.5 \%$ ); however, Ca supplementation to multiparous cows improved $\mathrm{P} / \mathrm{AI}$ at the first (control $=32.1, \mathrm{CaS} 1=38.6, \mathrm{CaS} 4=41.3 \%)$ and all artificial inseminations $($ control $=28.1, \mathrm{CaS} 1=35.3, \mathrm{CaS} 4=$ $40.5 \%$ ). These responses in $\mathrm{P} / \mathrm{AI}$ to $\mathrm{Ca}$ supplementation resulted in extended median days to pregnancy $($ control $=75, \mathrm{CaS} 1=100, \mathrm{CaS} 4=94 \mathrm{~d})$ and smaller proportion of pregnant cows $($ control $=89.3, \mathrm{CaS} 1=$ $83.9, \mathrm{CaS} 4=83.9 \%$ ) in primiparous cows, but shorter days to pregnancy $($ control $=115, \mathrm{CaS} 1=94$, CaS4 $=94 \mathrm{~d})$ and increased proportion of pregnant cows in multiparous cows $($ control $=67.0, \mathrm{CaS} 1=77.2, \mathrm{CaS} 4$ $=74.3 \%$ ). Risk of metritis depressed most measures of reproduction evaluated in the experiment. Results indicate that responses to oral Ca supplementation are conditional on parity and production potential of cows. Oral Ca supplementation was detrimental to reproduction in primiparous cows. On the other hand, Ca supplementation benefited reproduction in multiparous cows and milk yield in the cohort of multiparous cows of greater production potential.

Key words: calcium supplementation, dairy cow, milk yield, reproduction

\section{INTRODUCTION}

Subclinical hypocalcemia (SCH) is a prevalent metabolic problem in dairy cattle (Reinhardt et al., 2011; Ribeiro et al., 2013). Subclinical hypocalcemia reduces DMI and compromises energy metabolism (Martinez et al., 2014), which can have major implications for early lactation cows. Hypocalcemia exacerbates insulin resistance by impairing insulin release (Martinez et al., 2014), but also because of a direct effect of parathyroid hormone on adipocytes (Chang et al., 2009), which likely further compromises the catabolic state of dairy cows in the first weeks of lactation. The collective effects of SCH on dairy cows include reduced innate immune response (Martinez et al., 2014), impaired energy 
metabolism, and reduced reproductive performance (Chapinal et al., 2012; Martinez et al., 2012).

Subclinical hypocalcemia is a well-described risk factor for diseases in early lactation (Martinez et al., 2012), but it is also associated with reduced reproductive performance and increased risk of culling. Cows with SCH had reduced estrous cyclicity (Ribeiro et al., 2013), pregnancy at first AI (Chapinal et al., 2012), and extended median days to pregnancy (Martinez et al., 2012). The link between hypocalcemia and milk yield is less clear because many of the cows susceptible to hypocalcemia are also those that produce more milk. Cows with $\mathrm{SCH}$ produced more milk during the first weeks of lactation than those normocalcemic (Jawor et al., 2012; Gild et al., 2015), suggesting that affected cows might have a greater productive potential or that greater production increases the risk of low blood $\mathrm{Ca}$ because of increased losses in colostrum and milk. The potential negative effects of hypocalcemia on reproduction and production might be mediated by the increased incidence of diseases in cows with low blood $\mathrm{Ca}$ in the first days of lactation. Disease in early lactation is a major impediment for timely pregnancy in dairy cows (Santos et al., 2010; Ribeiro et al., 2013). In particular, inflammatory diseases such as metritis can depress reproduction by reducing establishment and maintenance of pregnancy in dairy cattle (Ribeiro et al., 2016). It is known that SCH is an important risk factor for metritis and other diseases (Martinez et al., 2012), and periparturient problems are highly prevalent in dairy farms, affecting 17 to $44 \%$ of Holstein cows (Dubuc et al., 2010; Santos et al., 2010). Therefore, one can hypothesize that the increased risk of diseases caused by SCH might compromise production and reproduction in dairy cows.

One method to increase blood $\mathrm{Ca}$ after calving is the administration of oral Ca salts. Several experiments have evaluated the effect of oral administration of different $\mathrm{Ca}$ salts on lactation and reproductive performance, and results were usually inconsistent. Stevenson et al. (1999) reported no effect of Ca supplementation on productive and reproductive performance in dairy cows, whereas Ledgard et al. (2004) reported reduced days to pregnancy in only 1 of 4 herds evaluated. Recently, Oetzel and Miller (2012) found interactions between oral Ca dosing postpartum and productive potential in multiparous cows. Therefore, it seems that benefits to supplemental $\mathrm{Ca}$ are dependent on the cohort of cows treated, which likely is related to their susceptibility to hypocalcemia and the detrimental effects the latter has on performance of dairy cows.

It was hypothesized that reducing $\mathrm{SCH}$ by oral supplementation with Ca salts improves lactation and reproductive outcomes in dairy cows. These benefits were thought to be observed in cohorts of cows that are more susceptible to hypocalcemia such as those at high risk of diseases or multiparous cows. Thus, the objectives of this experiment were to evaluate the effect of oral $\mathrm{Ca}$ supplementation in the early postpartum period on milk yield, pregnancy per AI $(\mathbf{P} / \mathbf{A I})$, and days to pregnancy in dairy cows of low or high risk of developing metritis. Of special interest was to identify potential cohorts of cows that might benefit more from Ca supplementation relative to production and reproduction.

\section{MATERIALS AND METHODS}

The experiment was conducted from September 2013 to July 2014 in a commercial dairy farm in California milking 5,226 cows during the experimental period and with a rolling herd average of $13,635 \mathrm{~kg}$ of $3.5 \%$ FCM. Cow enrollment occurred from October to December 2013 , and the last cow completed the $210 \mathrm{~d}$ observation in July of 2014. The farm was visited daily by the research team for identification of eligible cows, randomization of treatments, administration of treatments, diagnosis of diseases, and implementation of reproductive management from September 2013 to February 2014. After the last cow enrolled in the experiment received the first postpartum insemination, the farm was visited weekly for collection of data for milk production and reproductive performance. Primiparous and multiparous Holstein cows were housed in separate pens during the pre- and postpartum periods. Pre- and postpartum cows were fed once daily diets formulated to meet or exceed the suggested nutrient concentrations in rations for pre- and postpartum cows (NRC, 2001). Diets were fed as TMR and offered for ad libitum intake. The diet of prepartum parous cows was formulated to have a negative calculated dietary cation-anion difference $(-153 \pm 96 \mathrm{mEq} / \mathrm{kg})$ by addition of acidogenic salts. No acidogenic salts were added to the prepartum diet fed to nulliparous cows and the resulting dietary cation anion difference averaged $6 \pm 37 \mathrm{mEq} / \mathrm{kg}$. Details of the ingredient composition and nutrient content of the diets offered to pre- and postpartum to primiparous and multiparous cows are presented elsewhere (Martinez et al., 2016).

\section{Definition of Risk of Metritis, Experimental Design, and Treatments}

The day of calving was experiment $\mathrm{d} 0$. Primiparous $(\mathrm{n}=174)$ and multiparous $(\mathrm{n}=276)$ Holstein cows were evaluated on the day of calving and classified as having low (LRM) or high (HRM) risk of metritis. Cows considered LRM were those with normal calving 
(delivery of a live singleton without assistance followed by shedding the placenta in the first $12 \mathrm{~h}$ after calving). Cows considered HRM were those diagnosed with at least one of the following: dystocia, twins, stillbirth, vaginal-vulvar laceration, or retained placenta, as previously described (Martinez et al., 2012; Vieira-Neto et al., 2016).

The experiment was a randomized block design. The blocking criterion was parity group. Randomization sheets were created for primiparous and multiparous cows separately. A HRM cow was matched with a LRM cow based on lactation number and day of calving. Within primiparous or multiparous cow randomization, each pair of 2 cows, one LRM and one HRM, was randomly assigned to 1 of 3 treatments. Treatments were no Ca supplementation or sham bolus administration (control; $\mathrm{n}=150$ cows), $86 \mathrm{~g} / \mathrm{d}$ of Ca supplementation on d 0 and 1 postpartum (CaS1; $\mathrm{n}=150$ cows), or 86 $\mathrm{g} / \mathrm{d}$ of Ca supplementation on d 0 and 1 postpartum, followed by $43 \mathrm{~g} / \mathrm{d}$ on d 2, 3, and 4 postpartum (CaS4; $\mathrm{n}=150$ cows). Therefore, each block contained 6 cows as 3 pairs of one LRM and one HRM each. On experiment $\mathrm{d} 0$, treatments were administered in the morning. From d 1 to 4, treatments were administered in the mornings, between 0600 and $1000 \mathrm{~h}$. Calcium was supplemented using oral bolus each containing $43 \mathrm{~g}$ of Ca (Bovikalc; Boehringer Ingelheim Vetmedica Inc., St. Joseph, MO). Therefore, a total of 450 cows were enrolled in the experiment, and cows did not receive any other oral or parenteral Ca other than the treatments described above and the Ca contained within the diets. The only exception was when a cow developed clinical hypocalcemia, which was diagnosed in 2 control cows. Details of the minerals and energy metabolites measurements and disease outcomes evaluated during the early postpartum can be found in a companion paper (Martinez et al., 2016).

\section{Blood Sampling for Analysis of Total Ca and Definition of SCH}

Blood was sampled from all cows by puncture of the coccygeal blood vessels into evacuated tubes without anticoagulant at 0 and $34 \pm 4$ min relative to treatment on the day of calving, and again $30 \mathrm{~min}$ after treatment on $\mathrm{d} 1,2,3,4$, and in the morning of $\mathrm{d} 7$ and 10 postpartum. Control cows were sampled concurrently with cows in CaS1 and CaS4. Samples were allowed to clot and then placed on ice until processing. Details of sample handing and analysis of total Ca are presented in the companion paper (Martinez et al., 2016). Cows with concentrations of total $\mathrm{Ca}<2.125 \mathrm{~m} M$ were considered as having $\mathrm{SCH}$. The incidence and the daily prevalence of $\mathrm{SCH}$ were evaluated after treatments were initiated.

\section{Body Condition Score and Milk Yield}

Body condition was scored by 1 of 2 people previously trained using the 1 to 5 scale (Ferguson et al., 1994) according to the Elanco BCS chart (Elanco Animal Health, 2009). All cows were scored on the day of calving and at $32 \pm 3$ DIM, and changes in BCS were calculated for the first month postpartum. Cows were milked thrice daily and milk yield was recorded for every milking using electronic milk meters (Perfection 3000, Boumatic, Madison, WI). Daily milk yield was analyzed for the first $30 \mathrm{~d}$ and the first 5 mo postpartum. For the first 30 DIM, the daily production of each cow was used for analysis and $4.8 \%$ of the daily milk weights were handled as missing data because of lack of recording of production in 1 or all 3 milkings in the day. For the first 5 mo, daily values were averaged into weekly means for statistical analysis. In addition, a separate analysis including only multiparous cows was performed to evaluate the effect of Ca supplementation and duration of supplementation according to previous lactation 305-d mature equivalent (MEQ) milk yield. For the latter analysis, cows were categorized as above or below the average 305-d MEQ milk yield (14,003 $\mathrm{kg}$ ) in the previous lactation, and this category was included in the statistical model for analysis of milk production in the first 30 DIM.

\section{Reproductive Management}

The estrous cycle of all cows was synchronized with 2 intramuscular injections of $25 \mathrm{mg}$ of $\mathrm{PGF}_{2 \alpha}(5 \mathrm{~mL}$ of Lutalyse sterile solution, $5 \mathrm{mg} / \mathrm{mL}$ of dinoprost as tromethamine salt, Zoetis, Florham Park, NJ) given 14 d apart, at $38 \pm 3$ and $52 \pm 3$ DIM. After the second injection of $\mathrm{PGF}_{2 \alpha}$, which was considered the end of the voluntary waiting period, the tailheads of cows were painted with chalk daily, and removal of chalk was used as an indicator of estrus. Cows detected in estrus were inseminated on the same day, in the morning. Cows not inseminated by $63 \pm 3$ DIM were enrolled in the Ovsynch program. The timed AI protocol consisted of an intramuscular injection of $100 \mu \mathrm{g}$ of $\mathrm{GnRH}(2$ $\mathrm{mL}$ of Cystorelin, gonadorelin diacetate tetrahydrate equivalent to $43 \mu \mathrm{g}$ of gonadorelin/mL, Merial Ltd., Duluth, GA) on d $63 \pm 3$ postpartum, followed by an injection of $\mathrm{PGF}_{2 \alpha} 7 \mathrm{~d}$ later, and a second injection of GnRH $56 \mathrm{~h}$ after the $\mathrm{PGF}_{2 \alpha}$ treatment, at $72 \pm 3$ DIM. Cows were inseminated approximately $16 \mathrm{~h}$ after the second injection of $\mathrm{GnRH}$, on d $73 \pm 3$ postpartum. Cows that returned to estrus were reinseminated on the 
same day and considered nonpregnant to the previous AI. Cows diagnosed as nonpregnant at the pregnancy exam had the estrous cycle resynchronized with the Ovsynch protocol and were reinseminated within $10 \mathrm{~d}$ of nonpregnancy diagnosis.

\section{Reproductive Responses}

Resumption of estrous cyclicity postpartum was evaluated by ultrasonography using a portable ultrasound equipped with a 7.5-MHz linear transducer (Easi-Scan, BCF Technology, Rochester, MN) at $38 \pm 3$ and $52 \pm$ 3 DIM. Cows with at least one corpus luteum (CL) recorded in one or both observation days were considered to have resumed estrous cyclicity, whereas those without a visible CL in both evaluation days were considered anovular. Pregnancy was diagnosed by ultrasonography on d $32 \pm 3$ after each AI based on the presence of an amniotic vesicle with an embryo. Pregnant cows were re-examined for pregnancy by transrectal palpation 4 wk later, on d $60 \pm 3$ of gestation. The reproductive responses recorded were DIM at first $\mathrm{AI}, \mathrm{P} / \mathrm{AI}$ at first AI, pregnancy loss between 32 and $60 \mathrm{~d}$ of gestation, $\mathrm{P} / \mathrm{AI}$ to all AI performed in the first 210 DIM based on the diagnosis on d 60 after insemination, proportion of cows pregnant at 210 DIM, and days to pregnancy.

\section{Statistical Analysis}

The experiment followed a randomized complete block design, with parity group as the blocking factor and cow as the experimental unit. The sample size calculated is presented in a companion manuscript (Martinez et al., 2016). Briefly, we assumed that administration of Ca would reduce the risk of SCH by $40 \%$, which was anticipated to reduce metritis with potential benefits to production and reproduction. The final sample size (150 cow/treatment) provided sufficient experimental units to detect a 10-percentage-unit difference in $\mathrm{P} /$ $\mathrm{AI}$ given that the $\mathrm{P} / \mathrm{AI}$ for cows inseminated between December and May of the preceding year in the farm where the experiment was conducted was $35.8 \%(\alpha=$ $0.05 ; \beta=0.20)$.

Continuous data had residuals evaluated for distribution and homogeneity of variance. Transformation was applied before analysis if data deviated from normality. Milk yield, BCS, and DIM at first AI were analyzed by ANOVA using the MIXED procedure of SAS (SAS/ STAT version 9.3, SAS Institute Inc., Cary, NC). For data with repeated measures within experimental unit, the covariance structure with the smallest Akaike's information criterion was selected. The KenwardRoger method was used to calculate the approximate denominator degrees of freedom for the $F$ tests in the statistical models.

The statistical models used for analyses of continuous data included the fixed effects of treatment (control, CaS1, CaS4), risk of metritis group (HRM, LRM), parity (primiparous, multiparous), interactions between treatment and risk of metritis group, treatment and parity, and treatment and parity and risk of metritis group. For repeated measurements within the same experimental unit, the models also included the fixed effects of time (day or week), the interactions between time and the other fixed effects in the model, and the random effects of cow nested within treatment and block nested within parity. When data from only multiparous were analyzed, then the models excluded the effects of parity and included the category of previous lactation 305-d MEQ as above or below the mean value.

Binary data such as detection of estrus, incidence of estrous cyclic cows, P/AI, and pregnancy loss were analyzed by logistic regression using the GLIMMIX procedure of SAS (SAS/STAT version 9.3). The models included the fixed effects of treatment, risk of metritis group, parity, and interactions between treatment and risk of metritis group, treatment and parity, risk of metritis group and parity, and treatment and risk of metritis group and parity, and the random effect of block. All explanatory variables remained in the models. For analysis of daily prevalence of $\mathrm{SCH}$, the statistical model also included the fixed effects of day and interactions between day and the other variables in the model, and the random effect of cow nested within treatment. Pairwise comparisons among treatments, or between risk of metritis groups, or between parity groups on a given day were adjusted by the method of Tukey. An additional analysis was performed to determine the association between SCH and P/AI.

Days postpartum to pregnancy were analyzed with Cox's hazard regression method using the PHREG procedure of SAS (SAS/STAT version 9.3). The statistical models included the effects of treatment, risk of metritis group, parity, and interactions between treatment and risk of metritis group, treatment and parity, and treatment and risk of metritis group and parity. Nonsignificant $(P>0.10)$ interactions were dropped from the final model.

In all analyses, orthogonal contrasts were used to evaluate the effect of Ca supplementation (control vs. CaS1 + CaS4), duration of Ca supplementation (CaS1 vs. CaS4), interaction between Ca supplementation and risk of metritis, interaction between duration of $\mathrm{Ca}$ supplementation and risk of metritis, interaction between Ca supplementation and parity, and interaction between duration of Ca supplementation and parity. 
Table 1. Incidence and daily prevalence of subclinical hypocalcemia ( $\mathrm{SCH}$ ) in Holstein cows based on serum total Ca $<2.125 \mathrm{~m} M$ according to treatment, parity, and risk of metritis at calving

\begin{tabular}{|c|c|c|c|c|c|c|c|}
\hline \multirow[b]{2}{*}{ Item } & \multicolumn{3}{|c|}{ Treatment $^{1}$} & \multicolumn{2}{|c|}{ Parity } & \multicolumn{2}{|c|}{$\begin{array}{l}\text { Risk of metritis at } \\
\text { calving }\end{array}$} \\
\hline & Control & $\mathrm{CaS} 1$ & $\mathrm{CaS} 4$ & Primiparous & Multiparous & LRM & HRM \\
\hline Incidence of $\mathrm{SCH},{ }^{3} \%$ & $69.3^{\mathrm{a}}$ & $57.5^{\mathrm{b}}$ & $34.2^{\mathrm{c}}$ & $47.6^{\mathrm{d}}$ & $55.6^{\mathrm{d}}$ & $42.7^{\mathrm{g}}$ & $62.0^{1}$ \\
\hline \multicolumn{8}{|l|}{ Prevalence of $\mathrm{SCH}^{4} \%$} \\
\hline d 0 & $44.1^{\mathrm{a}}$ & $6.8^{\mathrm{b}}$ & $4.4^{\mathrm{b}}$ & $5.1^{\mathrm{e}}$ & $26.2^{\mathrm{d}}$ & $10.1^{\mathrm{f}}$ & $14.6^{6}$ \\
\hline d 4 & $17.5^{\mathrm{a}}$ & $21.4^{\mathrm{a}}$ & $6.3^{\mathrm{b}}$ & $11.2^{\mathrm{d}}$ & $16.4^{\mathrm{d}}$ & $7.8^{\mathrm{g}}$ & $22.7^{1}$ \\
\hline d 7 & $6.7^{\mathrm{a}}$ & $10.8^{\mathrm{a}}$ & $6.7^{\mathrm{a}}$ & $5.7^{\mathrm{d}}$ & $10.8^{\mathrm{d}}$ & $3.2^{\mathrm{g}}$ & $17.9^{9}$ \\
\hline d 10 & $6.2^{\mathrm{a}}$ & $6.0^{\mathrm{a}}$ & $9.4^{\mathrm{a}}$ & $5.5^{\mathrm{d}}$ & $9.0^{\mathrm{d}}$ & $2.7^{\mathrm{g}}$ & $17.4^{4}$ \\
\hline
\end{tabular}

${ }^{\mathrm{a}-\mathrm{c}}$ Within treatment in a given row, means with distinct superscripts differ after adjustment by Tukey $(P<0.05)$.

${ }^{\mathrm{d}, \mathrm{e}}$ Within parity in a given row, means with distinct superscripts differ after adjustment by Tukey $(P<0.05)$.

${ }^{\mathrm{f}, \mathrm{g}}$ Within risk of metritis at calving in a given row, means with distinct superscripts differ after adjustment by Tukey $(P<0.05)$.

${ }^{1} \mathrm{Control}=$ no Ca supplementation postpartum; CaS1 $=$ cows received $86 \mathrm{~g}$ of Ca per day on $\mathrm{d} 0$ and 1 postpartum; CaS4 $=$ cows received $86 \mathrm{~g}$ of Ca per day on $\mathrm{d} 0$ and 1 postpartum, and then $43 \mathrm{~g}$ of Ca per day on $\mathrm{d} 2,3$, and 4 postpartum.

${ }^{2}$ Low risk of metritis $(\mathrm{LRM})=$ cows that calved with no dystocia, singleton live calf, no retained placenta, and no vaginal laceration. High risk of metritis $(\mathrm{HRM})=$ cows that had at least one of the following: dystocia, twins, stillbirth, retained placenta, or vaginal laceration.

${ }^{3}$ Evaluated on d 0 to 3 postpartum in serum samples collected after the morning milking and 30 min after treatment in cows receiving oral Ca supplementation.

${ }^{4}$ Evaluated in the first 10 DIM in serum samples collected after the morning milking and 30 min after treatment in cows receiving oral Ca supplementation.

Statistical significance was considered at $P \leq 0.05$ and a tendency was considered at $P \leq 0.10$.

\section{RESULTS}

Of the 450 cows enrolled in the experiment, 3 pairs of primiparous cows (6 cows: 3 LRM and $3 \mathrm{HRM}$ ) were removed from the experiment because 3 LRM cows were found to have retained placenta after enrollment. Therefore, 444 cows remained in the experiment, 168 primiparous cows $(\mathrm{LRM}=84 ; \mathrm{HRM}=84)$ and 276 multiparous cows $(\mathrm{LRM}=138 ; \mathrm{HRM}=138)$. Out of the remaining cows, 442 had data on reproductive responses.

\section{Subclinical Hypocalcemia and Association with Reproduction}

The prevalence of SCH before any Ca supplementation on $\mathrm{d} 0$ was $44.6 \%$ and it tended $(P=0.06)$ to be less for CaS4 than CaS1 (control = 48.0, Cas1 $=$ 49.3, CaS4 $=36.5 \%$ ). Supplementing cows with oral Ca reduced the incidence and the daily prevalence of $\mathrm{SCH}$ (Table 1). The incidence of SCH was further reduced with extending the duration of $\mathrm{Ca}$ supplementation with CaS4. Cows in CaS1 had reduced daily prevalence of $\mathrm{SCH}$ on d 0 and 1, which correspond to the days of oral $\mathrm{Ca}$ administration for that treatment. Similar to
CaS1, cows in CaS4 had reduced prevalence of SCH up to the last day of oral Ca administration, 4 DIM.

An association between $\mathrm{SCH}$ and measures of reproductive performance was observed in the current experiment. Cows diagnosed with $\mathrm{SCH}$ tended to have reduced $(P=0.08) \mathrm{P} / \mathrm{AI}$ at first $\mathrm{AI}$ (normocalcemia $=$ 43.5 vs. $\mathrm{SCH}=36.8 \%)$ and also tended $(P=0.09)$ to have extended median days to pregnancy [normocalce$\operatorname{mia}=91(95 \% \mathrm{CI}=75-106)$ vs. $\mathrm{SCH}=101 \mathrm{~d}(95 \%$ $\mathrm{CI}=87-116)]$.

\section{Milk Yield}

Supplementation with Ca did not affect milk yield in the first $30 \mathrm{~d}$ of lactation, which averaged 32.3, 31.7, and $31.9 \pm 0.5 \mathrm{~kg} / \mathrm{d}$ for control, CaS1, and CaS4, respectively. Table 2 depicts the results for the statistical model for daily milk yield in the first 30 DIM for all cows. No interaction between Ca supplementation and risk of metritis or parity was observed for milk yield on the first 30 DIM. However, an interaction $(P=0.05)$ between duration of supplementation and risk of metritis was observed (Table 2); among cows at LRM, extending the length of supplementation improved milk yield $(\mathrm{CaS} 1=32.3$ vs. $\mathrm{CaS} 4=33.8 \pm$ $0.6 \mathrm{~kg} / \mathrm{d}$ ), whereas the opposite response was observed among cows at HRM $(\mathrm{CaS} 1=31.2$ vs. $\mathrm{CaS} 4=29.9$ $\pm 0.6 \mathrm{~kg} / \mathrm{d}$; Figure 1). Nevertheless, this interaction 
between duration of $\mathrm{Ca}$ supplementation and risk of metritis was temporary and no longer observed when production was analyzed for the first 5 mo in lactation (Figure 2). By 5 mo postpartum, cows averaged 40.4, 40.6 , and $40.5 \pm 0.5 \mathrm{~kg} / \mathrm{d}$ in control, CaS1, and CaS4, respectively, and no effects of Ca supplementation or duration of $\mathrm{Ca}$ supplementation were observed. In a separate analysis including only multiparous cows, an interaction $(P=0.03)$ between Ca supplementation and the previous lactation 305-d MEQ was detected for milk yield in the first 30 DIM (Figure 3). Cows with previous lactation production above average 305-d MEQ produced more milk when supplemented with $\mathrm{Ca}$ $($ control $=35.8, \mathrm{CaS} 1=38.5, \mathrm{CaS} 4=36.6 \pm 1.0 \mathrm{~kg} / \mathrm{d})$, whereas $\mathrm{Ca}$ supplementation reduced milk yield for multiparous cows with previous lactation production below the average 305-d MEQ (control = 35.2, CaS1 = $33.2, \mathrm{CaS} 4=32.4 \pm 1.0 \mathrm{~kg} / \mathrm{d}$ ). As expected, cows at LRM had greater $(P<0.01)$ milk yield than cows at HRM either on the first $30 \mathrm{~d}(33.4$ vs. $30.6 \pm 0.5 \mathrm{~kg} / \mathrm{d})$ or $5 \mathrm{mo}$ (41.2 vs. $39.7 \pm 0.5 \mathrm{~kg} / \mathrm{d})$ of lactation.

\section{Body Condition Score}

The body condition of cows did not differ among treatments at calving, and averaged $3.32 \pm 0.03$. Sup- plementation with $\mathrm{Ca}$ or duration of supplementation did not influence the BCS of cows on d 32 postpartum, which averaged $2.87 \pm 0.02$ (Table 3 ). The similar BCS at calving and d 32 among treatments resulted in no differences in BCS loss in the first 32 DIM because of either Ca supplementation or duration of Ca supplementation (control $=-0.43, \mathrm{CaS} 1=-0.42, \mathrm{CaS} 4=$ $-0.46 \pm 0.03)$. Cows at LRM lost less $(P=0.03)$ body condition than those at HRM ( -0.40 vs. $-0.47 \pm 0.03)$, which resulted in greater $(P<0.01)$ mean BCS on $\mathrm{d}$ 32 postpartum $(\mathrm{LRM}=2.91 \pm 0.02$ vs. $\mathrm{HRM}=2.84 \pm$ 0.02 ; Table 3$)$. Parity did not influence the mean BCS on d 32 (primiparous $=2.85 \pm 0.02$ vs. multiparous $=$ $2.89 \pm 0.02$; Table 4$)$, but primiparous cows lost more $(P<0.01)$ BCS in the first $32 \mathrm{~d}$ postpartum compared with multiparous cows $(-0.50$ vs. $-0.37 \pm 0.03)$. No interactions between Ca supplementation or duration of supplementation with parity or risk of metritis were observed.

\section{Reproductive Responses}

The percent of estrous cyclic cows by 52 DIM in the experimental population was $77.0 \%$. Supplementation with $\mathrm{Ca}$ or duration of supplementation did not affect the incidence of estrous cyclic cows, which averaged

Table 2. Model for daily milk yield $(\mathrm{kg} / \mathrm{d})$ in the first $30 \mathrm{~d}$ postpartum

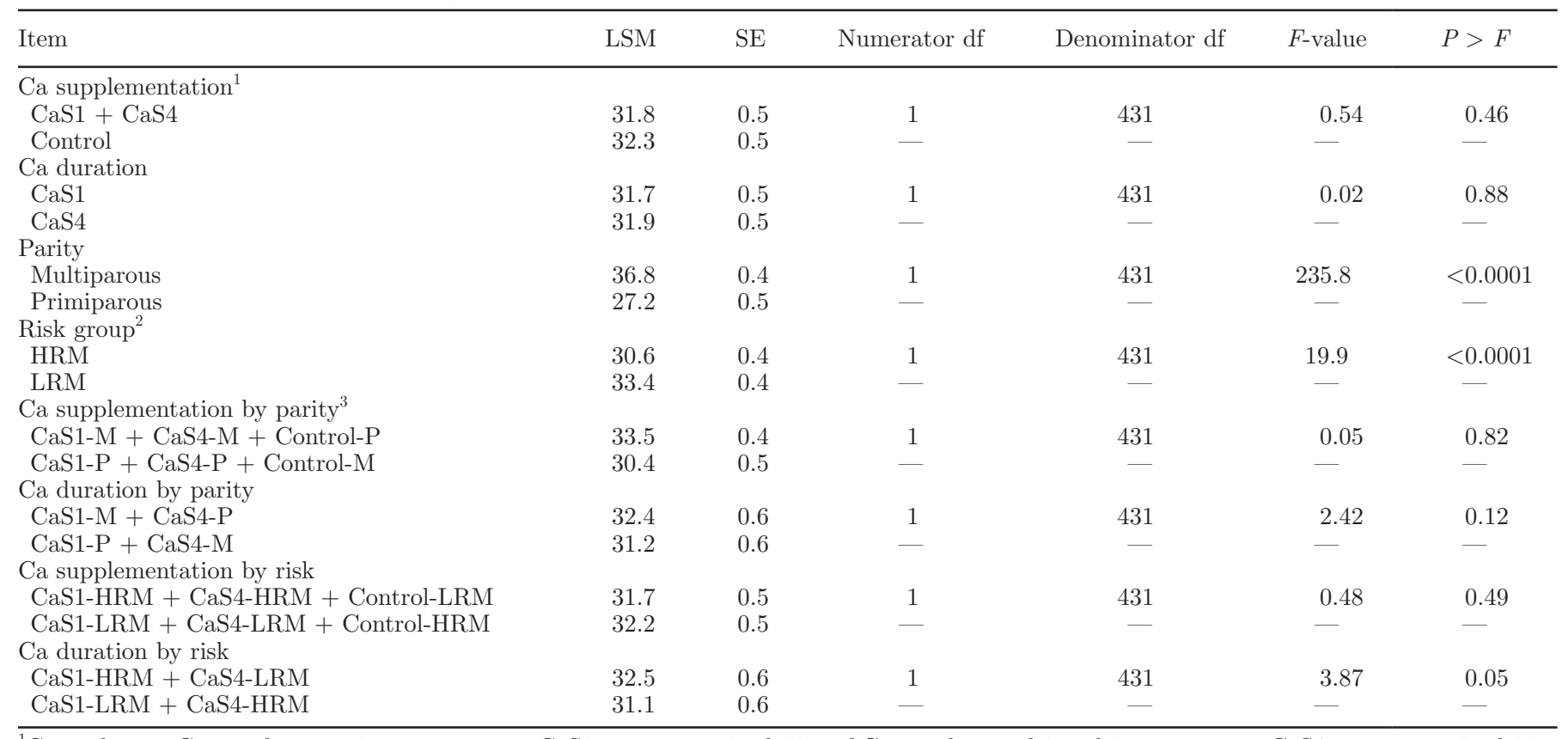

${ }^{1}$ Control $=$ no Ca supplementation postpartum; CaS1 = cows received $86 \mathrm{~g}$ of Ca per day on d 0 and 1 postpartum; CaS4 = cows received $86 \mathrm{~g}$ of Ca per day on d 0 and 1 postpartum, and then $43 \mathrm{~g}$ of Ca per day on $\mathrm{d} 2,3$, and 4 postpartum.

${ }^{2}$ Low risk of metritis $(\mathrm{LRM})=$ cows that calved with no dystocia, singleton live calf, no retained placenta, and no vaginal laceration. High risk of metritis $(\mathrm{HRM})=$ cows that had at least one of the following: dystocia, twins, stillbirth, retained placenta, or vaginal laceration.

${ }^{3} \mathrm{M}=$ multiparous; $\mathrm{P}=$ primiparous. 
75.9, 79.2, and $75.7 \%$ for control, CaS1, and CaS4, respectively (Table 3). Approximately $50.5 \%$ of the cows showed estrus and were inseminated after the second $\mathrm{PGF}_{2 \alpha}$ of the synchronization protocol and before enrollment in the Ovsynch timed AI program. Calcium supplementation or duration of supplementation did not affect the proportion of cows detected in estrus and inseminated, which averaged 51.8, 48.8, and 50.9\% for control, CaS1, and CaS4, respectively. Cows at HRM were less likely $(P<0.01)$ to be inseminated in estrus than those in LRM. Parity did not affect the proportion of cows inseminated in estrus (Table 4). No interactions were observed between Ca supplementation and risk of metritis or parity or between duration
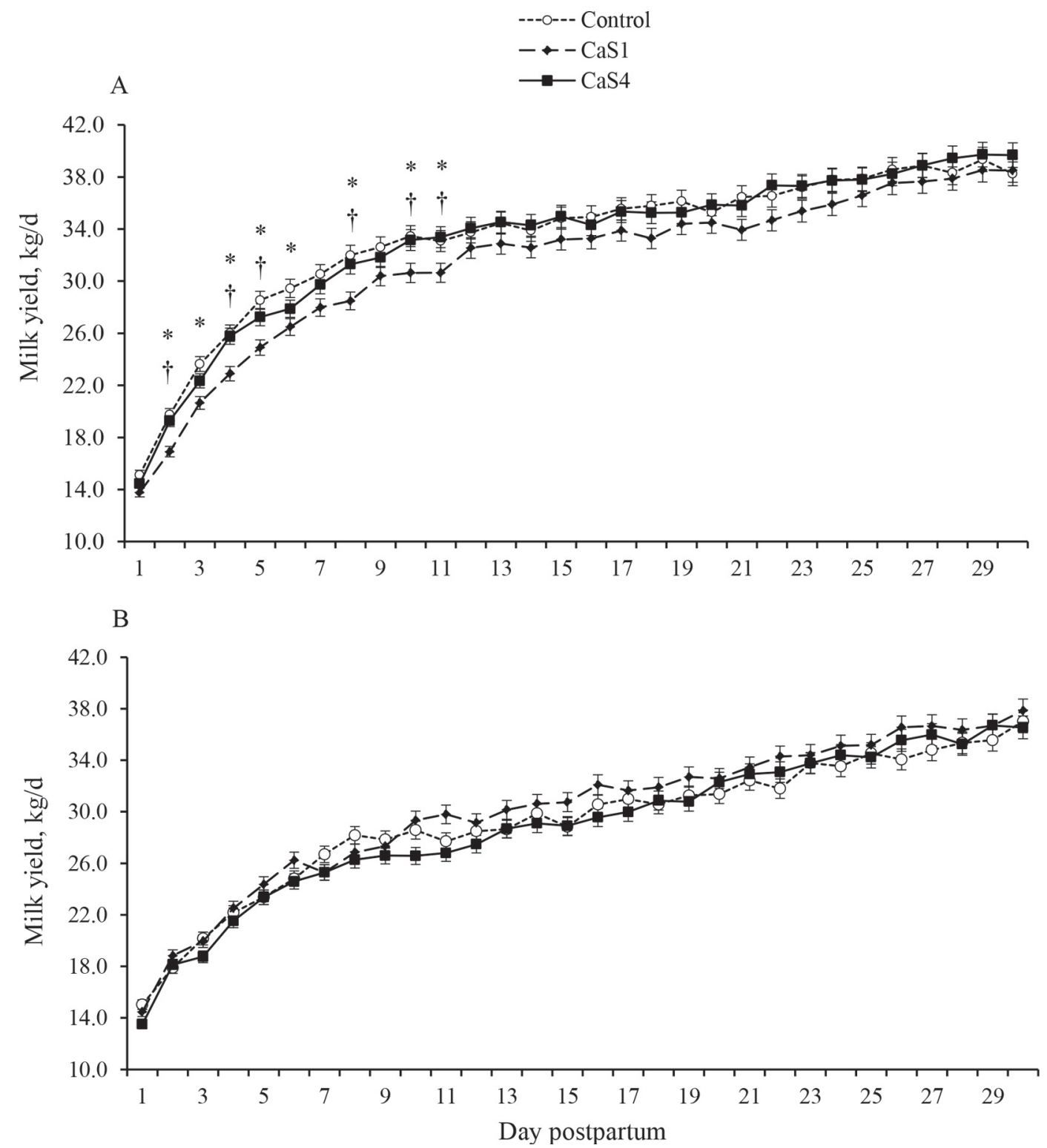

Figure 1. Milk yield $(\mathrm{kg} / \mathrm{d})$ during the first $30 \mathrm{~d}$ postpartum according to treatment and risk of metritis in Holstein cows. Control $=$ no Ca supplementation postpartum $(\mathrm{n}=148)$; CaS1 = cows received $86 \mathrm{~g}$ of Ca per day on d 0 and 1 postpartum $(\mathrm{n}=150)$; CaS4 $=$ cows received 86 $\mathrm{g}$ of Ca per day on d 0 and 1 postpartum, and then $43 \mathrm{~g}$ of Ca per day on $\mathrm{d} 2,3$, and 4 postpartum $(\mathrm{n}=150)$. Panel A, cows considered to be of low risk of metritis (LRM; calved with no dystocia, singleton live calf, no retained placenta, and no vaginal laceration); Panel B, cows considered to be of high risk of metritis (HRM; had at least one of the following: dystocia, twins, stillbirth, retained placenta, or vaginal laceration). Interaction between duration of Ca supplementation and risk of metritis $(P=0.05)$. ${ }^{*}$ Within day, control and CaS1 differ $(P=0.05)$. $\dagger$ Within day, CaS1 and CaS4 differ $(P<0.05)$. Milk yields averaged $32.8,30.8$, and $32.6 \mathrm{~kg} / \mathrm{d}$ for control, CaS1, and CaS4, respectively, in cows at low risk of metritis (A), and 28.8, 29.6, and $28.4 \mathrm{~kg} / \mathrm{d}$ in control, CaS1, and CaS4, respectively, in those of high risk of metritis (B). Error bars depict SEM. The pooled SEM for the interaction of treatment by risk group by day postpartum was $0.7 \mathrm{~kg} / \mathrm{d}$. 
of Ca supplementation and risk of metritis or parity. The days postpartum to first AI did not differ with Ca supplementation and averaged 65.4, 66.3, and $66.1 \pm$ 0.9 for control, CaS1 and CaS4, respectively.

The statistical model for $\mathrm{P} / \mathrm{AI}$ is depicted in Table 5 . An interaction $(P<0.01)$ between Ca supplementation and parity was observed for P/AI (Tables 4 and 5). Supplementing Ca to primiparous cows reduced P/AI on $\mathrm{d} 32$ and 60 , but the opposite response was observed in multiparous cows with oral Ca supplementation. Similar to first AI, an interaction $(P<0.01)$ between Ca supplementation and parity was observed for $\mathrm{P} /$ AI after all AI by 210 DIM; primiparous cows treated with $\mathrm{Ca}$ had reduced $\mathrm{P} / \mathrm{AI}$, but supplementation with Ca to multiparous cows improved P/AI after all AI (Table 4). Because of the opposing effects on $\mathrm{P} / \mathrm{AI}$, an interaction $(P=0.04)$ between Ca supplementation and parity was also observed for the rate of pregnancy up to $210 \mathrm{~d}$ postpartum (Table 6 ). Within primiparous cows, supplementing $\mathrm{Ca}$ increased the median days to pregnancy by $22 \mathrm{~d}$; however, for multiparous cows, Ca supplementation reduced the same interval by 21 d (Table 6; Figure 4). These differences in response to $\mathrm{Ca}$ supplementation based on parity resulted in a

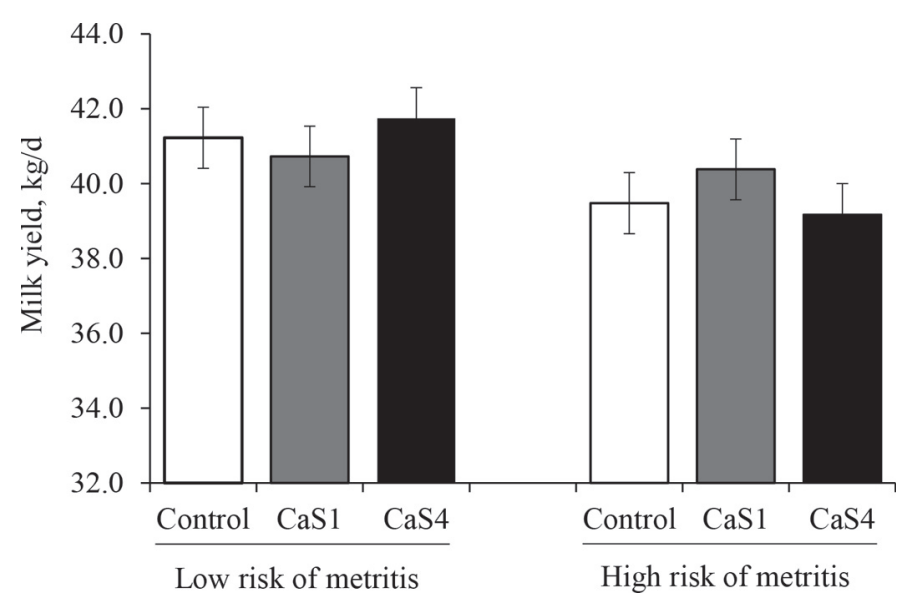

Figure 2. Milk yield $(\mathrm{kg} / \mathrm{d})$ during the first 5 mo postpartum according to treatment and risk of metritis in Holstein cows. Control = no Ca supplementation postpartum $(\mathrm{n}=148)$; $\mathrm{CaS} 1=$ cows received $86 \mathrm{~g}$ of Ca per day on d 0 and 1 postpartum $(\mathrm{n}=148)$; CaS4 $=$ cows received $86 \mathrm{~g}$ of $\mathrm{Ca}$ per day on $\mathrm{d} 0$ and 1 postpartum, and then 43 $\mathrm{g}$ of Ca per day on $\mathrm{d} 2,3$, and 4 postpartum $(\mathrm{n}=148)$. Low risk of metritis $(\mathrm{LRM})=$ cows that calved with no dystocia, singleton live calf, no retained placenta, and no vaginal laceration. High risk of metritis $(\mathrm{HRM})=$ cows that had at least one of the following: dystocia, twins, stillbirth, retained placenta, or vaginal laceration. Interaction between interaction between $\mathrm{Ca}$ supplementation and risk of metritis $(P=0.33)$, interaction between duration of Ca supplementation and risk of metritis $(P=0.33)$. The daily yields of milk in the first $5 \mathrm{mo}$ postpartum among cows with LRM averaged $41.2,40.7$, and $41.8 \mathrm{~kg} / \mathrm{d}$ in control, CaS1, and CaS4, respectively, and 39.5, 40.4, and $39.2 \mathrm{~kg} / \mathrm{d}$ for control, CaS1, and CaS4, respectively, among those with HRM Error bars depict SEM. The pooled SEM for the treatment by risk group interaction was $0.8 \mathrm{~kg} / \mathrm{d}$. reduced proportion of cows pregnant at 210 DIM in primiparous cows, but the same Ca supplementation increased the proportion of multiparous cows pregnant at 210 DIM (Table 6). Nevertheless, duration of supplementation with oral $\mathrm{Ca}$ had no effect on $\mathrm{P} / \mathrm{AI}$ at first or all AI. Treatment with oral Ca had no overall effect on pregnancy loss during the first $60 \mathrm{~d}$ of gestation. A tendency for interaction $(P=0.09)$ between duration of Ca supplementation and risk group was observed because for LRM, duration of oral Ca supplementation did not influence pregnancy loss, but extending supplementation with CaS4 tended to increase pregnancy loss in HRM cows (Table 3).

Cows of HRM had reduced $(P=0.05) \mathrm{P} / \mathrm{AI}$ at first AI based on the diagnosis on d 60 after AI and reduced $(P=0.03) \mathrm{P} / \mathrm{AI}$ at all AI compared with cows of LRM (Table 3). The negative effects on $\mathrm{P} / \mathrm{AI}$ resulted in a slower $(P<0.01)$ rate of pregnancy for cows of HRM than those of LRM which increased median days to pregnancy by 25 (Table 6). No interaction between Ca supplementation and risk group was detected for days to pregnancy.

\section{DISCUSSION}

The objectives of the present experiment were to evaluate the effects of 2 strategies for Ca supplementation on body condition, milk yield, and reproductive performance in dairy cows of low or high risk of developing metritis. Both oral Ca supplementation strategies used reduced the incidence and prevalence of $\mathrm{SCH}$ in dairy cows in the first days of lactation. It was hypothesized that a reduction in SCH would benefit lactation and reproductive performance because hypocalcemia is an important risk factor for early postpartum diseases that impair production and reproduction (Dubuc et al., 2010, 2011; Ribeiro et al., 2016). Results from the current experiment indicate that responses to oral Ca supplementation are conditional on parity and production potential of cows. Oral Ca was detrimental to reproduction in primiparous cows; however, Ca supplementation benefited reproduction in multiparous cows and milk yield in the cohort of multiparous cows of greater production potential.

Oral supplementation with $\mathrm{Ca}$ reduced the incidence and daily prevalence of SCH in cows and it was thought that improved Ca status in early lactation would benefit measures of reproduction. Nevertheless, administration of oral Ca had no effect on resumption of estrous cyclicity by 52 DIM or days postpartum to first AI. The incidence of estrous cyclic cows was similar to values reported in the literature for primiparous and multiparous cows (Santos et al., 2009). Although oral Ca reduced $\mathrm{SCH}$, it had mixed effects on postpartum health of cows 
depending on parity group (Martinez et al., 2016), and it did not influence changes in body condition. These results might explain the lack of effects on the incidence of estrous cyclic cows at 52 DIM. The lack of differences in days to first insemination with treatment is likely the result of similar resumption of postpartum estrous cyclicity combined with the reproductive management implemented on the farm. The proportions of cows that had ovulated by 52 DIM or detected in estrus after treatment with $\mathrm{PGF}_{2 \alpha}$ were similar among treatments.
In addition, cows not observed in estrus were enrolled in a timed AI protocol to ensure first insemination within the first $73 \mathrm{~d}$ postpartum. Collectively, the lack of differences in estrous cyclicity, detection of estrus, and the implementation of the timed AI protocol explain the similar DIM at first AI.

Cows of HRM were less likely to be detected in estrus than those of LRM, although the prevalence of cows that had resumed estrous cyclicity by 52 DIM did not differ between the 2 risk groups. Cows of HRM had
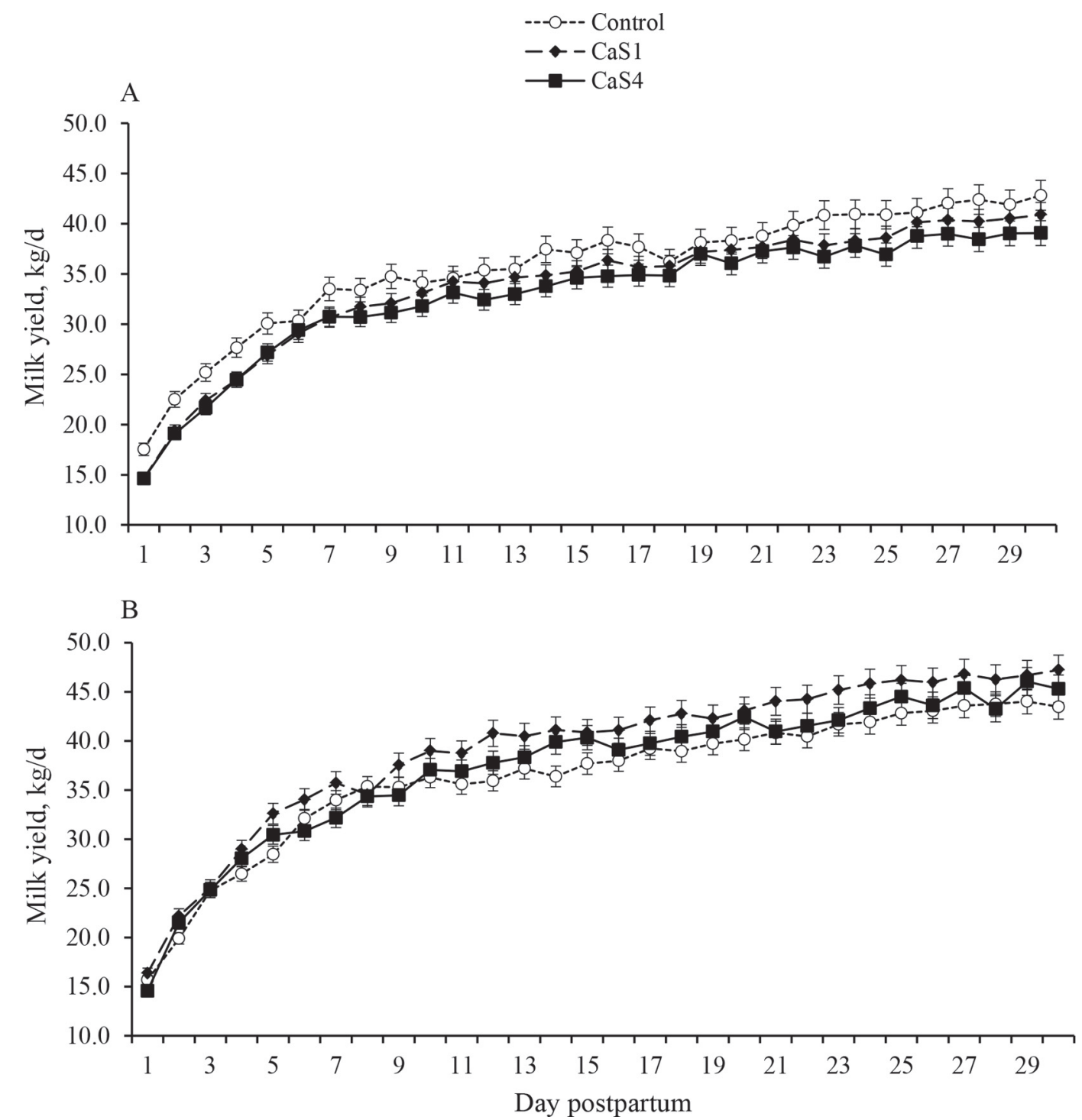

Figure 3. Milk yield $(\mathrm{kg} / \mathrm{d})$ during the first $30 \mathrm{~d}$ in milk of multiparous Holstein cows with previous lactation 305-d mature equivalent (MEQ) for milk below (A) or above (B) the group average. Control = no Ca supplementation postpartum $(\mathrm{n}=148)$; CaS1 $=$ cows received $86 \mathrm{~g}$ of Ca per day on d 0 and 1 postpartum $(\mathrm{n}=148)$; CaS4 $=$ cows received $86 \mathrm{~g}$ of Ca per day on d 0 and 1 postpartum, and then $43 \mathrm{~g}$ of Ca per day on $\mathrm{d} 2,3$, and 4 postpartum $(\mathrm{n}=148)$. The previous lactation 305-d MEQ milk yield averaged 14,003 kg. Interaction between Ca supplementation and previous lactation 305-d MEQ $(P=0.03)$. The daily yields of milk in the first $30 \mathrm{DIM}$ averaged $35.2,33.2$, and $32.4 \mathrm{~kg} / \mathrm{d}$ in control, CaS1, and CaS4 among the multiparous cows with previous lactation 305-d MEQ for milk below (A) the group average, and 35.8, 38.5 , and $36.6 \mathrm{~kg} / \mathrm{d}$ in control, CaS1, and CaS4, respectively, among the multiparous cows with previous lactation 305-d MEQ for milk above (B) the group average. Error bars depict SEM. The pooled SEM for the interaction of treatment by risk group by day postpartum was $1.1 \mathrm{~kg} / \mathrm{d}$. 

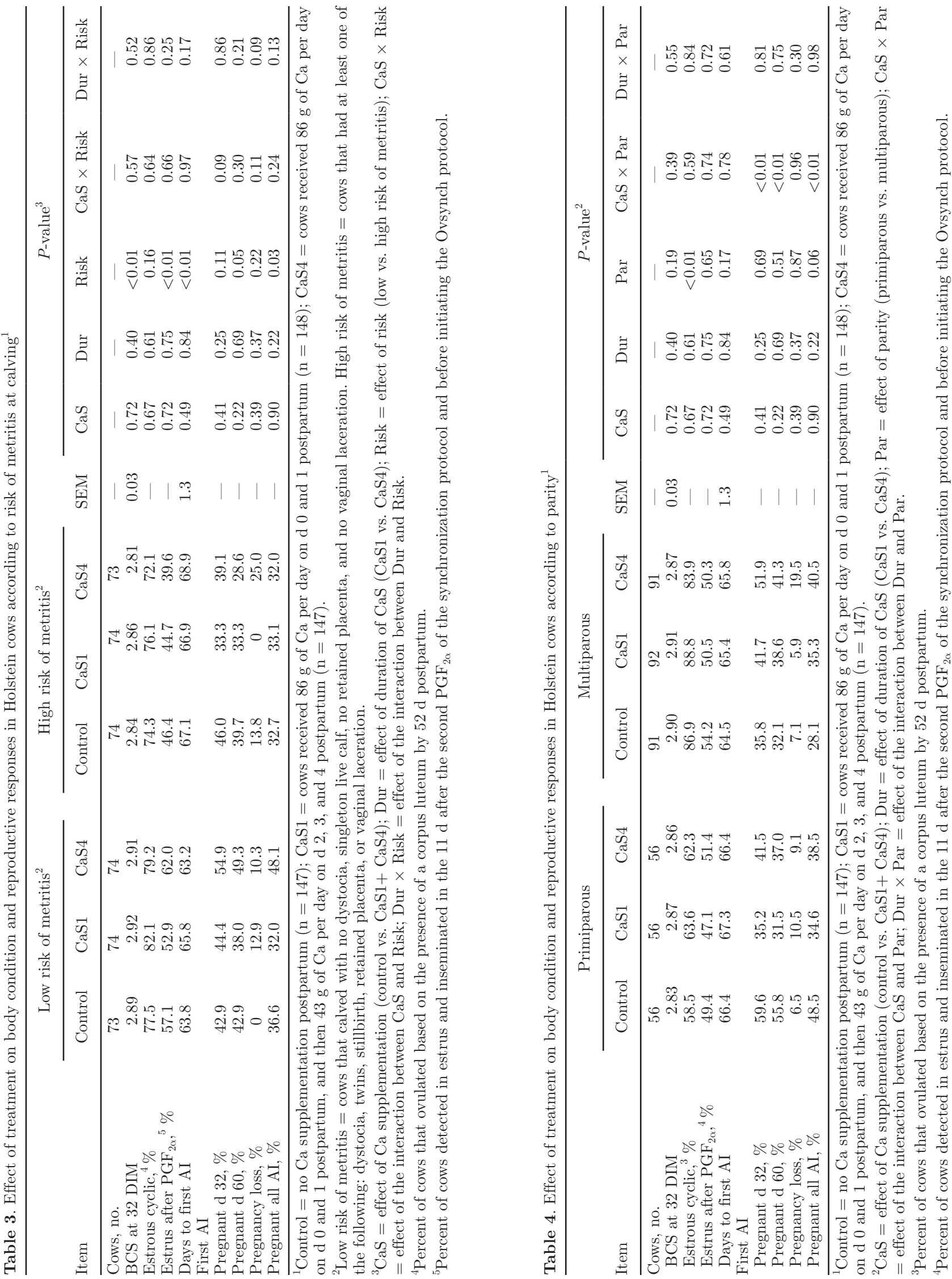
Table 5. Model for pregnancy at first AI based on diagnosis on d 60 after insemination ${ }^{1}$

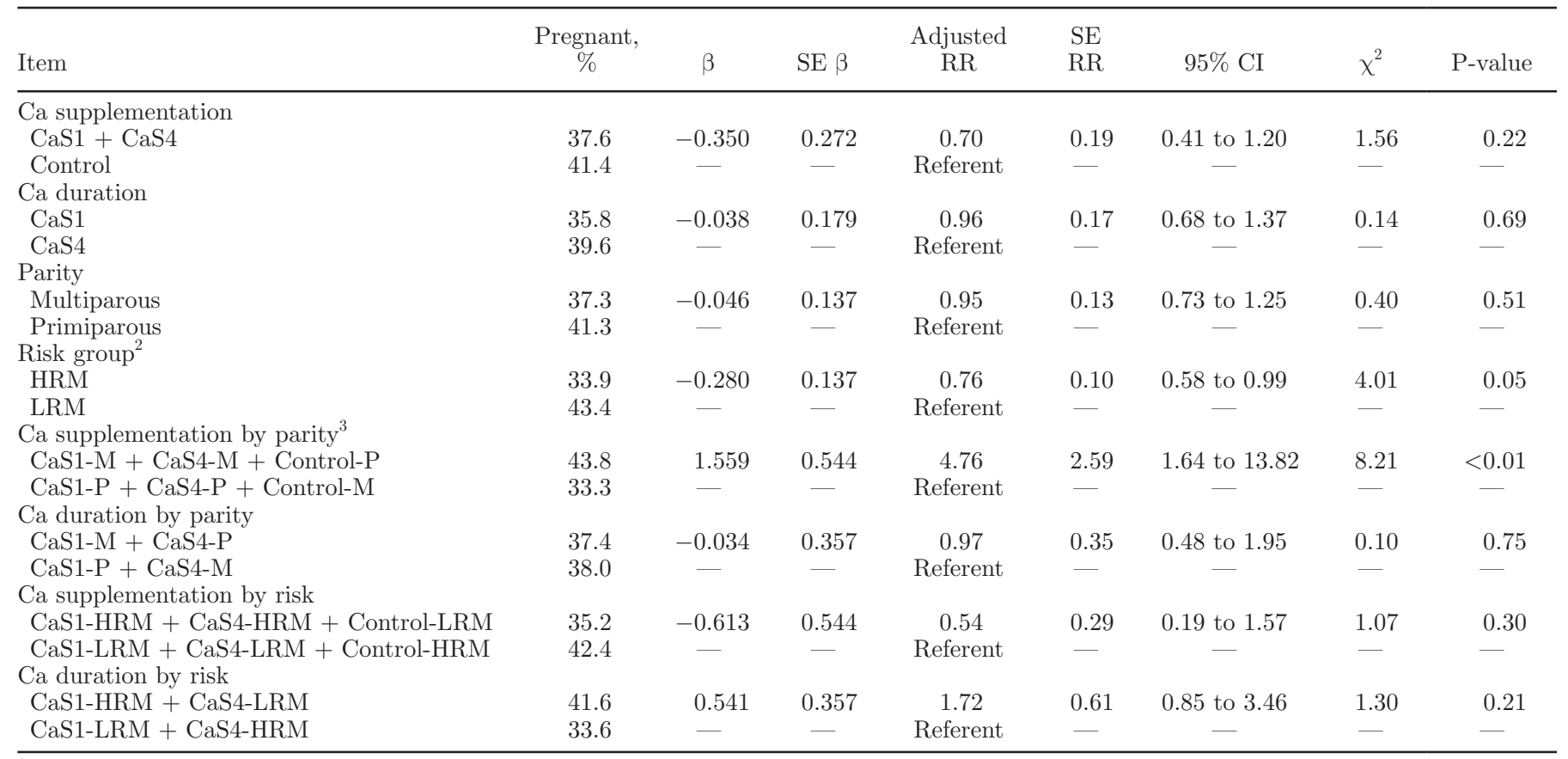

${ }^{1} \mathrm{RR}=$ relative risk. Control $=$ no Ca supplementation postpartum; CaS1 $=$ cows received 86 g of Ca per day on d 0 and 1 postpartum; CaS4 $=$ cows received $86 \mathrm{~g}$ of Ca per day on $\mathrm{d} 0$ and 1 postpartum, and then $43 \mathrm{~g}$ of Ca per day on $\mathrm{d} 2,3$, and 4 postpartum.

${ }^{2}$ Low risk of metritis $(\mathrm{LRM})=$ cows that calved with no dystocia, singleton live calf, no retained placenta, and no vaginal laceration. High risk of metritis $(\mathrm{HRM})=$ cows that had at least one of the following: dystocia, twins, stillbirth, retained placenta, or vaginal laceration.

${ }^{3} \mathrm{M}=$ multiparous; $\mathrm{P}=$ primiparous.

2.3-fold the morbidity in early lactation compared with LRM cows (Martinez et al., 2016), and many of the diseases that affected cows in the current experiment were of inflammatory nature. It is known that inflammation has long-lasting effects on reproduction (Ribeiro et al., 2016), and it is plausible to suggest that the increased incidence of diseases in these cows likely depressed their ability to express estrus, which reduced insemination after $\mathrm{PGF}_{2 \alpha}$ and extended the days postpartum to first AI.

Contrasting effects of Ca supplementation on reproduction were observed according to parity. In primiparous cows, supplemental $\mathrm{Ca}$ was deleterious to $\mathrm{P} / \mathrm{AI}$ and pregnancy rate, whereas in multiparous cows, oral Ca improved $\mathrm{P} / \mathrm{AI}$ and the rate of pregnancy, which, collectively, reduced the days postpartum to pregnancy

Table 6. Cox's regression analysis for days to pregnancy up to $210 \mathrm{~d}$ postpartum in Holstein cows ${ }^{1}$

\begin{tabular}{|c|c|c|c|c|}
\hline \multirow[b]{2}{*}{ Item } & \multicolumn{2}{|c|}{ Days to pregnancy } & \multirow{2}{*}{$\underset{\%}{\text { Pregnant, }}$} & \multirow{2}{*}{$\begin{array}{c}\mathrm{AHR}^{2} \\
(95 \% \mathrm{CI})\end{array}$} \\
\hline & Median (95\% CI) & Mean \pm SEM & & \\
\hline \multicolumn{5}{|c|}{ Primiparous } \\
\hline Control & $75(72$ to 96$)$ & $98.4 \pm 6.3$ & 89.3 & Referent \\
\hline CaS1 & $100(80$ to 121$)$ & $112.8 \pm 6.0$ & 83.9 & 0.68 (0.46 to 1.02$)$ \\
\hline $\mathrm{CaS} 4$ & $94(76$ to 118$)$ & $110.3 \pm 6.6$ & 83.8 & $0.76(0.51$ to 1.14$)$ \\
\hline \multicolumn{5}{|c|}{ Multiparous } \\
\hline Control & 115 (91 to 129$)$ & $117.5 \pm 5.7$ & 67.0 & Referent \\
\hline CaS1 & $94(75$ to 121$)$ & $111.6 \pm 5.4$ & 77.2 & $1.17(0.83$ to 1.65$)$ \\
\hline CaS4 & $94(76$ to 109$)$ & $111.3 \pm 6.0$ & 74.7 & $1.24(0.88$ to 1.75$)$ \\
\hline \multicolumn{5}{|c|}{ Risk of metritis } \\
\hline LRM & $83(76$ to 96$)$ & $104.1 \pm 3.3$ & 86.0 & Referent \\
\hline HRM & 108 (97 to 122$)$ & $121.0 \pm 3.9$ & 69.7 & $0.73(0.59$ to 0.91$)$ \\
\hline
\end{tabular}


and increased the proportion of pregnant cows at 210 DIM. In primiparous cows, administering oral Ca increased the incidence of metritis and morbidity in the first 30 DIM (Martinez et al., 2016). These results were unexpected as we initially hypothesized that reducing $\mathrm{SCH}$ would be beneficial to health of dairy cows and the fact that $\mathrm{SCH}$ is an important risk factor for peripartum diseases (Martinez et al., 2012).

In general, oral dosing of Ca salts in the first days postpartum has shown little benefit on subsequent reproductive performance of dairy cows (Melendez et al., 2003; Ledgard et al., 2004; Oetzel and Miller, 2012). Perhaps a more targeted approach is needed to identify cohorts of cows that are likely to respond to supplemental oral Ca. Also, the increase in blood $\mathrm{Ca}$ with oral supplementation is transient, with increases that last 2 to $8 \mathrm{~h}$ when 43 to $86 \mathrm{~g}$ are administered to dairy cows
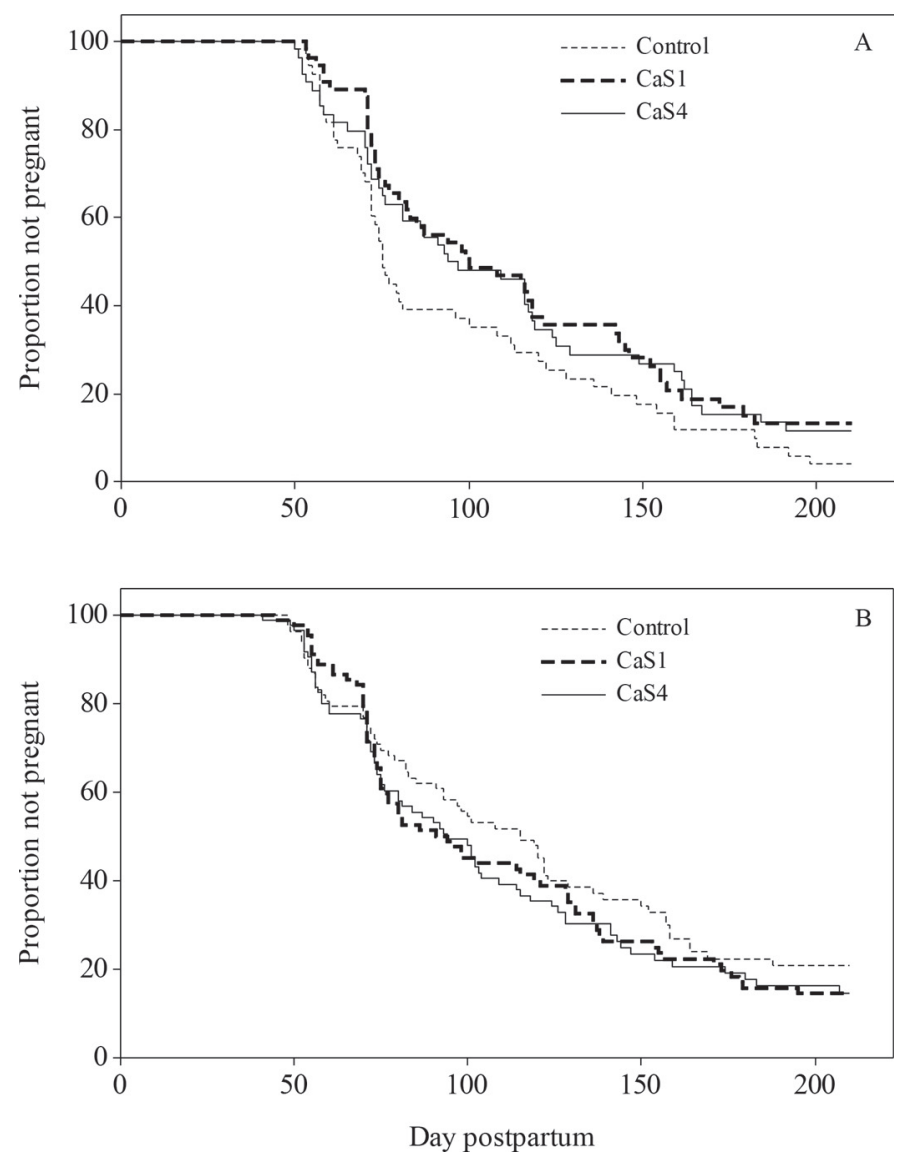

Figure 4. Survival curves for days to pregnancy in primiparous (A) or multiparous (B) Holstein cows receiving one of the following treatments: control $=$ no Ca supplementation postpartum $(\mathrm{n}=148)$ $\mathrm{CaS} 1=$ cows received $86 \mathrm{~g}$ of Ca per day on d 0 and 1 postpartum (n $=148)$; CaS $4=$ cows received $86 \mathrm{~g}$ of Ca per day on $\mathrm{d} 0$ and 1 postpartum, and then $43 \mathrm{~g}$ of Ca per day on $\mathrm{d} 2,3$, and 4 postpartum $(\mathrm{n}=$ 148). Interaction between Ca supplementation and parity $(P=0.04)$.
(Martinez et al., 2016). These shifts in blood concentrations of Ca might benefit cows with low blood Ca, but might also be detrimental to those with adequate concentrations because of the transient hypercalcemia.

In cattle, a follicle takes approximately 60 to $80 \mathrm{~d}$ to develop from primary to preovulatory (Lussier et al., 1987), and it is clear that events that take place in early lactation affect subsequent reproduction (Santos et al., 2009, 2010). Therefore, it is plausible that cows more susceptible to SCH might benefit from Ca supplementation such that restoring proper $\mathrm{Ca}$ concentrations might have later benefits to fertility. Calcium plays important roles on the oocyte, as changes in intracellular Ca concentration control oocyte maturation and activation during fertilization (Homa et al., 1993; Stricker and Smythe, 2003). Therefore, hypocalcemia in early lactation might influence the developing follicle and oocyte with a carryover effect when breeding initiates. Also, diseases depress fertility, particularly those that affect the reproductive tract (Dubuc et al., 2010; Santos et al., 2010). Many of those diseases are associated with inflammation, and inflammatory diseases have carryover negative effects on $\mathrm{P} / \mathrm{AI}$ and pregnancy loss that extend up to 4 mo (Ribeiro et al., 2016). In fact, cows considered to be of HRM had greater morbidity (Martinez et al., 2016) and depressed reproductive performance compared with cows of LRM. Furthermore, the benefit of $\mathrm{Ca}$ on increasing $\mathrm{P} / \mathrm{AI}$ and reducing days to pregnancy in multiparous cows seem to be mediated in part by improved cow health during the first month postpartum (Martinez et al., 2016). Multiparous cows treated with $\mathrm{Ca}$ had reduced $\mathrm{SCH}$ and incidence of diseases other than metritis and ketosis. An association was observed between $\mathrm{SCH}$ and morbidity because SCH increased in $40 \%$ the relative risk of morbidity in the first 30 DIM (normocalcemia $=36.4$ vs. $\mathrm{SCH}=$ $50.9 \%$ ). Therefore, it plausible to suggest that one of the mechanisms by which oral $\mathrm{Ca}$ administration improved $\mathrm{P} / \mathrm{AI}$ in multiparous cows was mediated by reductions in SCH and disease incidence, which are linked with a reduction in reproductive performance. Likewise, the increased morbidity observed in primiparous cows when they were supplemented with Ca postpartum reported in the companion manuscript (Martinez et al., 2016) could explain why $\mathrm{Ca}$ administered as in the current experiment might be detrimental to reproduction in cohorts of cows less susceptible to SCH. Recent work has shown that diseases of uterine as well as nonuterine origin have long-lasting effects on reproduction in dairy cows (Ribeiro et al., 2016). Disease in early lactation reduced fertilization and morula quality, impaired d 15 conceptus development and ability to signal pregnancy, altered conceptus transcriptome with upregulation of genes linked to inflammation, and ultimately, reduced 
$\mathrm{P} / \mathrm{AI}$ and increased pregnancy loss of cows receiving AI or embryo transfer (Ribeiro et al., 2016).

The conflicting responses between primiparous and multiparous cows to oral supplementation with $\mathrm{Ca}$ are likely related to their susceptibility to hypocalcemia (Horst et al., 2005; Reinhardt et al., 2011), as well as the differences in response to the same dose of Ca (Martinez et al., 2016). The increase in blood concentration of iCa with oral administration to primiparous cows was twice that observed for multiparous cows receiving the same amount of oral Ca (Martinez et al., 2016). It is hypothesized that the large diurnal variations in blood $\mathrm{Ca}$ in cows less susceptible to $\mathrm{SCH}$ might have been detrimental to peripartum health, which could have contributed to the reduced reproductive performance in primiparous cows treated with Ca. Also, the oral $\mathrm{Ca}$ administration affected acid-base status with a compensated metabolic acidosis; perhaps primiparous cows are more sensitive to the potential negative effects of metabolic acidosis during early lactation on health that subsequently affect reproduction. Collectively, it is suggested that larger changes in blood Ca associated with increased incidence of diseases in primiparous cows treated with oral Ca likely explain the reduced reproductive performance in $\mathrm{CaS} 1$ and CaS4.

In spite of the increments in blood Ca (Martinez et al., 2016), and the reduction in $\mathrm{SCH}$, oral supplementation did not influence the change in body condition in the first $32 \mathrm{~d}$ postpartum. One of the negative effects of hypocalcemia is a reduction in DMI (Martinez et al., 2014), which could exacerbate measures of energy balance and increase body condition loss (Santos et al., 2010). It is known that changes in BCS usually are influenced by the nutritional and health status of dairy cows in early postpartum (Santos and Ribeiro, 2014), and minimizing hypocalcemia was thought to have an effect on BCS on d 32 postpartum, which was not observed.

Milk yield in the first 30 DIM or 5 mo of lactation was, in general, unaffected by Ca supplementation. However, supplementing cows on the day of calving and again on d 1 postpartum reduced milk production in the first 30 DIM compared with CaS4 in cows considered to be of LRM. On the other hand, multiparous cows of greater potential for production based on previous lactation 305-d MEQ milk yield benefited from Ca supplementation, whereas those with less potential for production had depressed milk yield when receiving oral Ca. It is important to highlight that changes in milk yield with treatment disappeared as the lactation progressed. Because SCH can depress intake and increase the risk of peripartum diseases (Martinez et al., 2012, 2014; Ribeiro et al., 2013), it was thought that minimizing suboptimal concentrations of $\mathrm{Ca}$ in the first days postpartum would benefit milk production. The fact that the only differences observed occurred in the first 30 DIM suggests that the effect of Ca supplementation on performance is subtle and time dependent. Oetzel and Miller (2012) observed minor benefits from $43 \mathrm{~g}$ of oral $\mathrm{Ca}$ administered once in the first hours after calving and repeated $12 \mathrm{~h}$ later. Interestingly, the authors also detected an interaction between $\mathrm{Ca}$ supplementation and previous lactation milk yield as observed in the current experiment. Supplementing cows with previous lactation production below the average caused a numerical decrease in milk yield, whereas cows ranked as previous lactation milk yield above average had increased production in the first month when supplemented with Ca. Cows with greater production potential are more likely to suffer from hypocalcemia in early lactation (Gild et al., 2015), and they might be a target group that responds to supplementation. Indeed, cows with SCH have increased milk yield during the first month postpartum (Jawor et al., 2012), reinforcing the concept that higher producing cows are more likely to have suboptimal blood $\mathrm{Ca}$ and benefit more from strategies that minimize hypocalcemia. It is important to mention that in the current experiment and in that of Oetzel and Miller (2012), the increased milk yield in multiparous cows of greater milk potential was only observed in the first month postpartum. At 5 mo postpartum, the average daily yields of milk of cows in all treatments were similar and the interactions with risk of metritis and production potential were no longer significant.

\section{CONCLUSIONS}

Supplementation with oral Ca had no effect on the change of body condition in the first $32 \mathrm{~d}$ postpartum. Although supplemental Ca did not affect milk yield in the first $5 \mathrm{mo}$ of lactation, interactions with risk of metritis and production potential in multiparous cows were observed in the first $30 \mathrm{~d}$ of lactation. Within multiparous cows, those with greater potential for production benefited from supplemental $\mathrm{Ca}$, whereas cows of less production potential had depressed milk yield when they received oral Ca. Dosing primiparous cows with oral $\mathrm{Ca}$ was detrimental to $\mathrm{P} / \mathrm{AI}$ and rate of pregnancy; however, the same strategy to multiparous cows improved $\mathrm{P} / \mathrm{AI}$ and increased pregnancy rate. Supplementation with oral Ca reduced the incidence and daily prevalence of $\mathrm{SCH}$, and the latter was associated with a reduction in $\mathrm{P} / \mathrm{AI}$ and extended days open. Collectively, these results indicate that oral Ca supplementation after calving should be used judiciously and it may be recommended only to multiparous cows. On the other hand, the supplementation regimen with the 
doses used in the present experiment should not be administered to primiparous cows because of the potential negative effects on reproduction and lack of benefits to productive performance.

\section{ACKNOWLEDGMENTS}

The authors thank the owners and staff of River Ranch farms (Hanford, CA) for the use of their cows and facilities. We thank Lucas Oliveira, Matheus Pansani, Nienke Vande Burgwal, Mariska Bosman, and Patrícia Carneiro (University of Florida, Gainesville) for assistance with the conduct of the experiment. Financial support for this project was provided by a grant from the Southeast Milk Inc. Checkoff Program (Belleview, FL).

\section{REFERENCES}

Chang, E., S. S. Donkin, and D. Teegarden. 2009. Parathyroid hormone suppresses insulin signaling in adipocytes. Mol. Cell Endocrinol. 307:77-82.

Chapinal, N., M. E. Carson, S. J. LeBlanc, K. E. Leslie, S. Godden, M. Capel, J. E. P. Santos, M. W. Overton, and T. F. Duffield. 2012. The association of serum metabolites in the transition period with milk production and early-lactation reproductive performance. J. Dairy Sci. 95:1301-1309.

Dubuc, J., T. F. Duffield, K. E. Leslie, J. S. Walton, and S. J. LeBlanc. 2010. Risk factors for postpartum uterine diseases in dairy cows. J. Dairy Sci. 93:5764-5771.

Dubuc, J., T. F. Duffield, K. E. Leslie, J. S. Walton, and S. J. Leblanc. 2011. Effects of postpartum uterine diseases on milk production and culling in dairy cows. J. Dairy Sci. 94:1339-1346.

Elanco Animal Health. 2009. The 5-point body condition scoring system. Bulletin AI 10752. Elanco Animal Health, Greenfield, IN.

Ferguson, J. D., D. T. Galligan, and N. Thomsen. 1994. Principal descriptors of body condition score in Holstein cows. J. Dairy Sci. 77:2695-2703.

Gild, C., N. Alpert, and M. van Straten. 2015. The influence of subclinical hypocalcemia on production and reproduction parameters in Israeli dairy herds. Isr. J. Vet. Med. 70:16-21.

Homa, S. T., J. Carroll, and K. Swann. 1993. The role of calcium in mammalian oocyte maturation and egg activation. Hum. Reprod. 8:1274-1281.

Horst, R. L., J. P. Goff, and T. A. Reinhardt. 2005. Adapting to the transition between gestation and lactation: Differences between rat, human and dairy cow. J. Mammary Gland Biol. Neoplasia 10:141-156.

Jawor, P. E., J. M. Huzzey, S. J. LeBlanc, and M. A. G. von Keyserlingk. 2012. Associations of subclinical hypocalcemia at calving with milk yield, and feeding, drinking, and standing behaviors around parturition in Holstein cows. J. Dairy Sci. 95:1240-1248.

Ledgard, S. F., G. D. Pitman, and J. D. Morton. 2004. Effect of calcium supplementation on milk production and hypocalcaemia. Pages 69-74 in Proc. 66th Conf. New Zealand Grassland Association, Ashburton, New Zealand.. http://www.grassland.org.nz/ index.php.
Lussier, J. G., P. Matton, and J. J. Dufour. 1987. Growth rates of follicles in the ovary of the cow. J. Reprod. Fertil. 81:301-307.

Martinez, N., C. A. Risco, F. S. Lima, R. S. Bisinotto, L. F. Greco, E. S. Ribeiro, F. Maunsell, K. Galvão, and J. E. P. Santos. 2012 Evaluation of peripartal calcium status, energetic profile, and neutrophil function in dairy cows at low or high risk of developing uterine disease. J. Dairy Sci. 95:7158-7172.

Martinez, N., L. D. P. Sinedino, R. S. Bisinotto, R. Daetz, C. Lopera, C. A. Risco, K. N. Galvão, W. W. Thatcher, and J. E. P. Santos. 2016. Effects of oral calcium supplementation on mineral and acid-base status, energy metabolites, and health of postpartum dairy cows. J. Dairy Sci. 99:8397-8416. http://dx.doi.org/10.3168/ jds.2015-10527.

Martinez, N., L. D. P. Sinedino, R. S. Bisinotto, E. S. Ribeiro, G. C. Gomes, F. S. Lima, L. F. Greco, C. A. Risco, K. N. Galvão, D. Taylor-Rodriguez, J. P. Driver, W. W. Thatcher, and J. E. P. Santos. 2014. Effect of induced subclinical hypocalcemia on physiological responses and neutrophil function in dairy cows. J. Dairy Sci. 97:874-887.

Melendez, P., G. Donovan, C. Risco, R. Littell, and J. Goff. 2003. Effect of calcium-energy supplements on calving-related disorders, fertility and milk yield during the transition period in cows fed anionic diets. Theriogenology 60:843-854.

NRC. 2001. Nutrient Requirements of Dairy Cattle. 7th rev. ed. Natl. Acad. Press, Washington, DC.

Oetzel, G. R., and B. E. Miller. 2012. Effect of oral calcium bolus supplementation on early-lactation health and milk yield in commercial dairy herds. J. Dairy Sci. 95:7051-7065.

Reinhardt, T. A., J. D. Lippolis, B. J. McCluskey, J. P. Goff, and R. L. Horst. 2011. Prevalence of subclinical hypocalcemia in dairy herds. Vet. J. 188:122-124.

Ribeiro, E. S., G. Gomes, L. F. Greco, R. L. A. Cerri, A. Vieira-Neto, P. L. J. Monteiro Jr., F. S. Lima, R. S. Bisinotto, W. W. Thatcher, and J. E. P. Santos. 2016. Carryover impact of postpartum inflammatory diseases on developmental biology and fertility in lactating dairy cows. J. Dairy Sci. 99:2201-2220.

Ribeiro, E. S., F. S. Lima, L. F. Greco, R. S. Bisinotto, A. P. A. Monteiro, M. Favoreto, H. Ayres, R. S. Marsola, N. Martinez, W. W. Thatcher, and J. E. P. Santos. 2013. Prevalence of periparturient diseases and impacts on fertility of seasonally calving grazing dairy cows supplemented with concentrates. J. Dairy Sci. 96:5682-5697.

Santos, J. E. P., R. S. Bisinotto, E. S. Ribeiro, F. S. Lima, L. F. Greco, C. R. Staples, and W. W. Thatcher. 2010. Applying nutrition and physiology to improve reproduction in dairy cattle. Soc. Reprod. Fertil. Suppl. 67:387-403.

Santos, J. E. P., and E. S. Ribeiro. 2014. Impact of animal health on reproduction of dairy cows. Anim. Reprod. 11:254-269.

Santos, J. E. P., H. M. Rutigliano, and M. F. Sá Filho. 2009. Risk factors for resumption of postpartum estrous cycles and embryonic survival in lactating dairy cows. Anim. Reprod. Sci. 110:207-221.

Stevenson, M. A., N. B. Williamson, and D. W. Hardon. 1999. The effects of calcium supplementation of dairy cattle after calving on milk, milk fat and protein production, and fertility. N. Z. Vet. J. 47:53-60.

Stricker, S. A., and T. L. Smythe. 2003. Endoplasmic reticulum reorganizations and $\mathrm{Ca}^{2+}$ signaling in maturing and fertilized oocytes of marine protostome worms: The roles of MAPKs and MPF. Development 130:2867-2879.

Vieira-Neto, A., F. S. Lima, J. E. P. Santos, R. D. Mingoti, G. S. Vasconcellos, C. A. Risco, and K. N. Galvão. 2016. Vulvovaginal laceration as a risk factor for uterine disease in postpartum dairy cows. J. Dairy Sci. 99:4629-4637. 